Artikel Penelitian

\title{
Analisis Kadar Arsen (As) pada Sayur Kubis Hijau (Brassica oleracea L.) Pasca Erupsi Gunung Sinabung
}

Boby Cahyady, Muhammad Taufik*, Suharman

Departemen Kimia, Fakultas Matematika dan IImu Pengetahuan Alam, Universitas Sumatera Utara, Medan, Indonesia, 20115

\section{INFO ARTIKEL}

Sejarah Artikel

Diterima 24 Desember 2020

Direvisi 2 Februari 2021

Tersedia online 15 Juni 2021

* Penulis korespondensi:

muhammad.taufik@usu.ac.id

\section{ABSTRAK}

Mount Sinabung has had an impact on the lives of surrounding farmers after the eruption. One of the negative impacts is the exposure of plants and animals around them to dangerous chemical compounds, especially heavy metals. This work aimed to analyze the levels of arsenic (As) in green cabbage (Brassica oleracea L.) which was exposed after two months of the eruption. The sampling method was done using a simple random sampling technique at five points. The digestion process was carried out using hydrochloric acid and nitric acid. Arsenic analysis was performed using the atomic absorption spectroscopy (AAS) at $193.7 \mathrm{~nm}$ with vapor hydride generation accessories. Concentration of arsenic exposed to green cabbage at five sampling points was $0.4102,0.4936,0.4501,0.6425$, and 0.6534 $\mathrm{mg} / \mathrm{Kg}$. The results obtained were lower than the maximum limit of arsenic contamination in vegetables, namely $1.0 \mathrm{mg} / \mathrm{Kg}$ based on SNI No. 7387:2009.

Keywords: arsenic, Brassica oleracea L, AAS, SNI, Mount Sinabung

Gunung Sinabung memiliki pengaruh kepada kehidupan petani di sekitarnya pasca erupsi. Salah satu dampak negatifnya adalah terpaparnya tumbuhan dan hewan di sekitar terhadap senyawa kimia yang berbahaya, khususnya logam berat. Penelitian ini bertujuan untuk menganalisis kadar arsen (As) yang terdapat pada sayur kubis hijau (Brassica oleracea L.) yang terpapar setelah dua bulan erupsi. Pengambilan sampel dilakukan dengan menggunakan teknik simple random sampling di lima titik. Proses destruksi dilakukan dengan menggunakan asam klorida dan asam nitrat. Analisis arsen dilakukan dengan menggunakan atomic absorption spectroscopy (AAS) pada panjang gelombang 193,7 nm yang dilengkapi vapour hydride generation accessories. Kadar arsen yang terpapar pada sayur kubis hijau pada lima titik pengambilan sampel berturut turut sebesar 0,$4102 ; 0,4936 ; 0,4501 ; 0,6425$, dan 0,6534 mg/Kg. Kadar arsen yang diperoleh lebih rendah dari batas maksimum cemaran arsen dalam sayuran yakni $1,0 \mathrm{mg} / \mathrm{Kg}$ berdasarkan SNI No. 7387:2009.

Kata kunci: arsen, Brassica oleracea L., AAS, SNI, Gunung Sinabung

\section{Pendahuluan}

Gunung Sinabung merupakan gunung berapi yang terdapat di Dataran Tinggi Karo, Kabupaten Karo, Sumatra Utara, Indonesia [1]. Gunung ini adalah dua gunung berapi yang aktif di Sumatra Utara [2]. Ketinggian Gunung Sinabung berada pada 2451 meter. Gunung ini meletus pertama kali pada 27 Agustus 2010 dan terus aktif sampai tahun 2020. Letusan Gunung Sinabung menghasilkan kolom erupsi berwarna putih kelabu setinggi 200-5000 m dari atas puncak [3]. Secara geografis, Gunung Sinabung terletak pada posisi koordinat 3,10 LU dan 98,23 BT, dengan ketinggian puncak $2460 \mathrm{~m}$ dari permukaan laut [4]. 
Sayuran merupakan bahan makanan pokok yang dikonsumsi sehari-hari oleh masyarakat dimana didalamnya banyak terkandung zat gizi seperti vitamin dan mineral $[5,6]$. Sayuran biasanya diolah atau dimasak terlebih dahulu sebelum dikonsumsi. Namun, ada juga beberapa jenis sayuran yang dikonsumsi langsung (sebagai lalapan) tanpa harus dimasak sebelumnya, seperti selada dan kol [7]. Tumbuhan termasuk sayur-sayuran seperti kentang, sawi dan wortel dapat terpapar oleh zat-zat pencemar seperti partikel dan gas. Partikel banyak dilepaskan oleh industri adalah timbal dan kadmium. Hal yang sama juga dapat terjadi akibat peristiwa erupsi.

Masalah pencemaran lingkungan sudah tidak asing lagi bagi kita. Adanya bahan-bahan pencemar yang bersifat toksik di lingkungan dapat membahayakan kehidupan. Tanaman dapat menjadi mediator penyebaran logam berat pada makhluk hidup karena masuknya logam tersebut pada tumbuhan melalui akar dan mulut daun (stoma). Sayur-sayuran sebagai bahan makanan baik pada manusia maupun hewan menyebabkan berpindahnya logam yang terpapar didalamnya seperti arsen, timbal, kadmium, kromium dan seng masuk ke dalam tubuh makhluk hidup lainnya [3].

Logam berat merupakan unsur logam dengan berat molekul tinggi yaitu lebih dari $5 \mathrm{~g} / \mathrm{cm}^{3}$ [8]. Logam berat dalam kadar rendah umumnya sudah beracun bagi tumbuhan, hewan dan manusia. Beberapa logam berat yang sering mencemari habitat adalah merkuri, kromium, arsen, kadmium dan timbal. Arsen merupakan bahan kimia dan metaloid paling beracun yang ditemukan di alam. Unsur ini menjadi perhatian karena dapat menyebabkan toksisitas dan karsinogenik [9]. Paparan arsen pada manusia dapat dalam bentuk anorganik dan organik. Keberadaan arsen di lingkungan dapat terjadi sebagai zat alami dan kontaminasi dari aktivitas manusia. Arsen dapat ditemukan di air, udara, makanan, dan tanah termasuk dari letusan gunung berapi, kontaminasi tambang, penggunaan pestisida dan pupuk [3].

Efek toksisitas arsen telah banyak diketahui, akan tetapi tingkat toksisitasnya bergantung pada bentuk organik atau anorganik senyawa arsen [10]. Senyawa arsen dalam bentuk anorganik lebih beracun daripada organik. Arsen bersifat karsinogen karena paparan jangka panjang dapat mengakibatkan peningkatan risiko untuk berbagai karsinoma termasuk kulit, kandung kemih, paru-paru, ginjal, hati, dan prostat [9]. Efek arsen berhubungan dengan perubahan dalam gastrointestinal, kardiovaskular, hematologi, paru, saraf, imunologi, reproduksi dan efek jangka panjang arsen dapat menyebabkan kanker. Menurut International Agency for Research on Cancer (IARC), arsen dimasukkan pada kelas pertama sebagai bahan karsinogen dan dapat menyebabkan kanker paru-paru, kulit dan kanker kandung kemih pada manusia tanpa nilai ambang batas minimum dimana dalam jumlah kecil arsen dapat berbahaya bagi manusia [11, 12].

Pada penelitian ini, daun kubis hijau yang diduga terpapar oleh logam berat pasca erupsi Gunung Sinabung dipreparasi, diekstraksi dan dianalisis. Hazimah dan Triwuri [13] telah meneliti tentang logam arsen pada depot air minum isi ulang di Kota Batam dengan atomic absorption spectrometry (AAS). Hasil penelitian menunjukkan bahwa kadar logam arsen pada air $<0,0001 \mathrm{mg} / \mathrm{L}$. Harahap [9] telah menganalisis logam arsen dalam sayur bayam menunjukkan hasil bahwa pada bayam hijau (Amaranthus tricolor) diperoleh konsentrasi arsen sebesar $0,35 \mathrm{mg} / \mathrm{kg}$ sedangkan bayam merah (Blitum rubrum) diperoleh konsentrasi arsen sebesar $0,40 \mathrm{mg} / \mathrm{kg}$. Senyawa arsen diduga terpapar dalam kubis petani yang tepapar erupsi Gunung Sinabung. Pada penelitian ini akan dikembangkan metode spektroskopi dalam menganalisis daun kubis hijau pasca erupsi Gunung Sinabung dengan AAS.

\section{Bahan dan Metode}

\subsection{Bahan}

Bahan yang digunakan adalah asam nitrat $65 \%$ (Sigma Aldrich), standard arsen $500 \mathrm{~mL}$ (Germany), asam klorida 37\% (Merck), dan natrium hidroksida 97\% (Sigma Aldrich).

\subsection{Pengumpulan Sampel}

Sampel kubis hijau diambil dari lahan pertanian masyarakat yang berada di Jalan Udara Desa Gajah Kecamatan Berastagi dengan jarak dari Gunung Sinabung $\pm 50 \mathrm{~m}$. Sampel diambil menggunakan metode simple random sampling pada lima titik kemudian dimasukkan dalam wadah berbahan selulosa.

\subsection{Destruksi Sampel}

Masing-masing sampel ditimbang sebanyak $50 \mathrm{~g}$ lalu dikeringkan dalam oven pada suhu $100^{\circ} \mathrm{C}$ selama 3 jam. Selanjutnya, sampel dimasukkan ke dalam furnace pada suhu $400^{\circ} \mathrm{C}$ selama 4 jam. Setelah dingin, sampel dilarutkan dengan campuran asam nitrat 65\% dan asam klorida 37\% dengan perbandingan 5:2. Kemudian, campuran dipanaskan di atas hotplate hingga sampel larut. Larutan sampel dipindahkan ke dalam labu takar $100 \mathrm{~mL}$ dan ditambahkan aquademineral hingga tanda batas. Larutan siap dianalisis dengan atomic absorption spectroscopy (AAS) pada panjang gelombang 193,7 nm yang dilengkapi dengan vapour hydride generation accessories. 


\subsection{Pembuatan Kurva Standar}

Larutan baku induk arsen $(1000 \mu \mathrm{g} / \mathrm{mL}$ ) dipipet $10 \mathrm{~mL}$ lalu dimasukkan ke dalam labu ukur $100 \mathrm{~mL}$ dan dicukupkan hingga garis tanda dengan aquademineral (konsentrasi $100 \mathrm{ppm}$ ). Kemudian, dipipet $5 \mathrm{~mL}$ lalu dimasukkan ke dalam labu ukur $500 \mathrm{~mL}$ dan dicukupkan hingga garis tanda dengan aquademineral (konsentrasi $1 \mu \mathrm{g} / \mathrm{mL}$ ). Dari konsentrasi $1 \mu \mathrm{g} / \mathrm{mL}$ kemudian dilakukan proses pengenceran menjadi konsentrasi 0,$0 ; 0,2 ; 0,4 ; 0,6$ dan $0,8 \mu \mathrm{g} / \mathrm{mL}$ kemudian diukur absorbansinya dengan AAS pada panjang gelombang 193,7 nm. Nilai absorbansi dan konsentrasi akan diplotkan untuk memperoleh kurva kalibrasi kemudian dihitung menggunakan persamaan regresi.

\subsection{Penentuan Kadar Arsen}

Sampel hasil destruksi dianalisis kadar arsen menggunakan AAS yang dilengkapi dengan vapour hydride generation accessories pada panjang gelombang 193,7 nm. Hasil analisis dicatat dan dibuat grafik hubungan antara absorbansi dengan konsentrasi (ppm) lalu dihitung konsentrasi arsen dalam sampel.

\section{Hasil dan Pembahasan}

Sayuran merupakan semua jenis tanaman atau bagian dari tanaman yang bisa diolah menjadi makanan [9]. Salah satu sayuran yang bisa dikonsumsi secara langsung atau tanpa dimasak yaitu kubis. Di Sumatera Utara, produsen sayuran terbesar berasal dari Kabupaten Kabanjahe. Komoditi sayuran segar telah bertahun-tahun dihasilkan untuk didistribusikan ke daerah lain bahkan sampai ke mancanegara. Sayuran biasanya diolah atau dimasak terlebih dahulu sebelum dikonsumsi, walaupun begitu, banyak sayuran yang juga dikonsumsi secara langsung sebagai lalapan misalnya kubis [7]. Persyaratan sayuran untuk dikonsumsi ini harus disesuaikan dengan standar yakni SNI No. 7387:2009. Pada penelitian ini, sayuran kubis hijau diambil dari kebun petani yang berada di Jalan Udara Kecamatan Brastagi untuk ditentukan kadar arsen pada lima titik pengambilan sampel.

Preparasi sampel sayuran kubis hijau dilakukan dengan menggunakan metode destruksi kering dengan cara sebanyak $0,5 \mathrm{~g}$ lalu dikeringkan dalam oven pada suhu $100^{\circ} \mathrm{C}$ selama 3 jam. Selanjutnya, sampel dimasukkan ke dalam furnace pada suhu $400^{\circ} \mathrm{C}$ selama 4 jam. Setelah dingin, sampel dilarutkan dengan campuran asam nitrat $65 \%$ dan asam klorida $37 \%$ dengan perbandingan $5: 2$, kemudian dipanaskan di atas hotplate hingga sampel larut. Larutan sampel dipindahkan ke dalam labu takar $25 \mathrm{~mL}$ dan tambahkan aquademineral hingga tanda batas. Larutan dianalisis dengan AAS pada panjang gelombang 193,7 nm yang dilengkapi dengan vapour hydride generation accessories.

Pada penelitian ini, asam nitrat $65 \%$ dan asam klorida $37 \%$ berfungsi untuk menguraikan sampel menjadi bentuk yang lebih sederhana sedangkan aquademineral berfungsi untuk mencuci larutan sampel yang tertinggal di kertas saring. Metode destruksi kering dilakukan untuk memutuskan ikatan antara senyawa organik dengan logam yang dianalisis. Asam nitrat ini juga bersifat oksidator kuat sehingga dapat menguraikan sampel menjadi unsur-unsur yang lebih sederhana. Nilai absorbansi dan konsentrasi dari sampel ditentukan menggunakan AAS pada panjang gelombang 193,7 nm. Pemilihan panjang gelombang maksimum bertujuan untuk menghasilkan absorbansi radiasi yang baik dan mencegah gangguan dari unsur-unsur lain yang akan mempengaruhi kadar arsen [9].

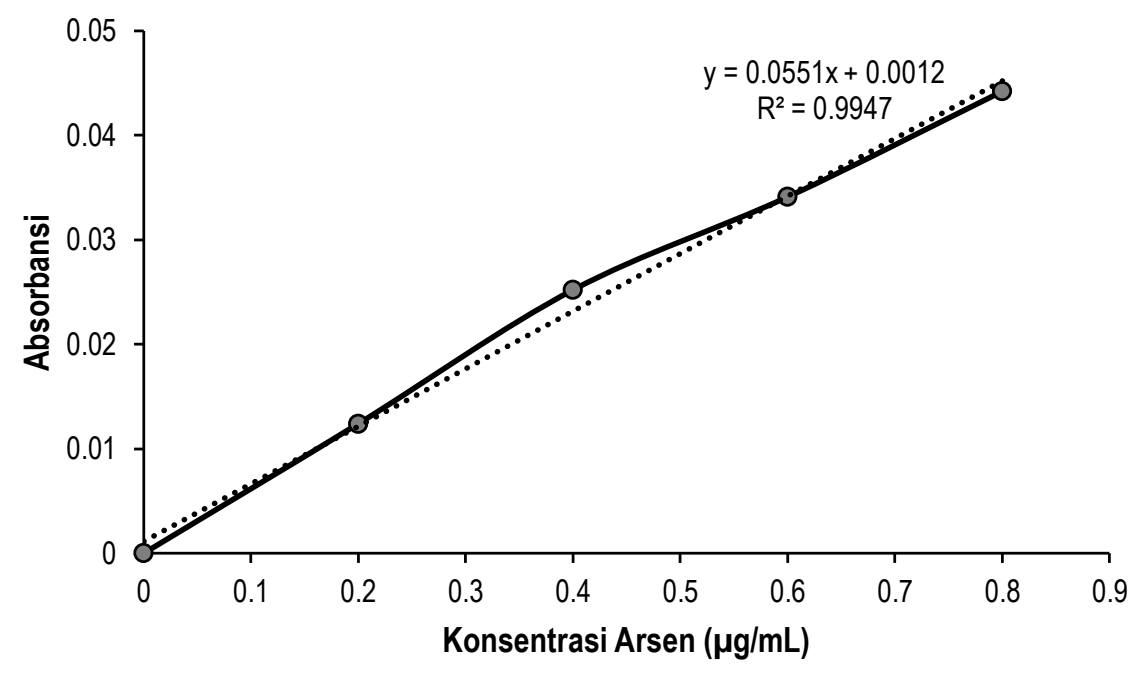

Gambar 1. Kurva larutan seri standar arsen 
Gambar 1. menunjukkan kurva seri standar arsen yang digunakan pada AAS. Persamaan garis lurus yang diperoleh adalah $y=0,0551 x+0,0012$ dengan koefisien korelasi $R^{2}=0,9947$. Data ini menunjukkan adanya hubungan atau korelasi positif antara konsentrasi dengan absorbansi yang dihasilkan. Hasil penelitian yang dilakukan diperoleh kadar arsen dalam kubis hijau (Brassica oleracea L) untuk titik 1, 2, 3, 4, dan 5 (Gambar 2). Berdasarkan Gambar 2, dapat diketahui bahwa konsentrasi kubis hijau yang diambil di lima titik adalah 0,$4102 ; 0,4936 ; 0,4501 ; 0,6425$ dan $0,6534 \mathrm{mg} / \mathrm{Kg}$, secara berturutturut. Konsentrasi arsen masing-masing titik ini masih relatif rendah jika dibandingkan dengan batas maksimum cemaran logam untuk buah dan sayur yaitu sebesar $1 \mathrm{mg} / \mathrm{kg}$ (SNI No. 7387:2009).

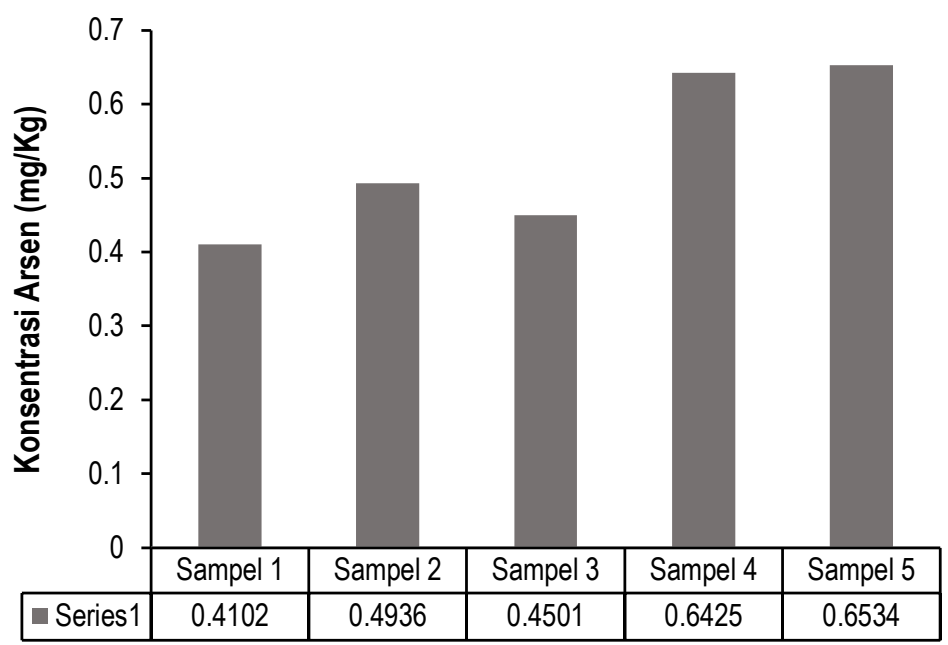

Gambar 2. Konsentrasi sampel kubis pada lima titik pengambilan sampel.

Kadar arsen yang mencemari kubis hijau tidak melebihi batas yang ditetapkan sehingga kubis hijau tersebut masih layak dan aman dikonsumsi [14]. Akan tetapi, jika konsumsi kubis hijau yang tercemar secara terus menerus akan mengakibatkan akumulasi arsen dalam tubuh yang memiliki dampak yang sangat berbahaya yaitu gangguan gastrointestinal, kerusakan pada jaringan otak bahkan kematian [15]. Arsen adalah logam berat yang menyebabkan keracunan bila terakumulasi dalam tubuh manusia [8].

Pada penelitian ini, arsen telah terdeteksi pada sayuran kubis hijau pasca erupsi Gunung Sinabung. Arsen sebagian besar terakumulasi oleh organ tanaman, yaitu daun, batang, akar, dan akar umbi-umbian. Jika proses akumulasi ini berlangsung secara terus-menerus dalam jangka waktu lama dapat mencapai jumlah yang membahayakan kesehatan manusia. Arsen yang masuk ke dalam tubuh dapat merusak kesehatan dengan berbagai cara seperti pengurangan sel-sel darah merah, penurunan sintesis hemoglobin dan penghambatan sintesis heme yang menimbulkan anemia. Secara umum, mekanisme timbulnya anemia yaitu akibat timbal yaitu akibat terbentuknya senyawa dengan enzim. Kompleks yang terbentuk menjadi tidak aktif yang berakibat terhambatnya sintesis darah merah $(\mathrm{Hb})$ dan menimbulkan anemia [16]. Hal yang sama senyawa arsen akan menyebabkan penyakit kanker [17].

\section{Kesimpulan}

Kadar arsen yang terpapar pada sayur kubis hijau (Brassica oleracea L.) pasca erupsi Gunung Sinabung dapat dianalisis menggunakan metode spektroskopi dengan AAS dan penyiapan sampel menggunakan metode destruksi. Kadar arsen yang diperoleh pada lima titik pengambilan sampel berturut turut adalah 0,$4102 ; 0,4936 ; 0,4501 ; 0,6425$, dan 0,6534 $\mathrm{mg} / \mathrm{Kg}$. Hasil yang diperoleh lebih rendah dari batas maksimum cemaran arsen dalam sayuran yakni $1,0 \mathrm{mg} / \mathrm{Kg}$ (SNI No. 7387:2009).

\section{Ucapan Terima Kasih}

Penulis mengucapkan terima kasih kepada Rektor Universitas Sumatera Utara yang telah memberikan dana penelitian melalui Penelitian Dosen Muda Tahun 2019 dengan Kontrak No. 318/UN5.2.3.1/PPM/KP-TALENTA USU/2019 Tanggal 2 April 2019. 


\section{Daftar Pustaka}

[1] Z. Alfian, E. Z. Nasution, \& M. Taufiq, "Qualitative and Quantitative Analysis of Heavy Metal and Mineral of Volcanic Ashmount Sinabung by Using Inductively Coupled Plasma ( Icp-Oes )," Der Pharma Chemica, vol. 9, no. 5, pp. 1822, 2017.

[2] N. F. Sinuhaji, "Analisis Logam Berat dan Unsur Hara Debu Kabupaten Karo Vulkanik Gunung Sinabung Kabupaten Karo - Sumatera Utara," Skripsi, Universitas Sumatera Utara, Medan, 2011.

[3] I. Kusmartini, W. Y. N. Syahfitri, S. Kurniawati, D. D. Lestiani, \& M. Santoso, "Elemental Characterization of Mt. Sinabung Volcanic Ash, Indonesia by Neutron Activation Analysis," Journal of Physics: Conference Series, vol. 860, no. $012005,2017$.

[4] C.-W. Lee, Z. Lu, \& J. W. Kim, "Monitoring Mount Sinabung in Indonesia Using Multi-Temporal InSAR," Korean Journal of Remote Sensing, vol. 33, no. 1, pp. 37-46, 2017.

[5] A. Arif, "Pengaruh Bahan Kimia terhadap Penggunaan Pestisida Lingkungan," Jurnal Farmasi, vol. 3, no. 4, pp. 134143, 2015.

[6] S. K. Pratiwi, A. Lorensia, \& R. V. Suryadinata, "Asupan Vitamin C dan E dengan SQ-FFQ terhadap Fungsi Paru Perokok dan Non-Perokok," Jurnal Media Kesehatan Masyarakat Indonesia, vol. 14, no. 2, pp. 101-107, 2018.

[7] I. W. Arsanti, A. L. Sayekti, \& A. M. Kiloes, "Analisis Rantai Nilai Komoditas Kubis (Brassica oleracea L ): Studi Kasus di Sentra Produksi Kabupaten Karo," Jurnal Hortikultura, vol. 27, no. 2, pp. 269-278, 2017.

[8] M. Nasir, Sulastri, \& M. M. Hilda, "Analisis Kadar Logam Timbal dan Arsenik dalam Tanah dengan Spektrometri Serapan Atom," Jurnal IPA dan Pembelajaran IPA, vol. 02, no. 02, pp. 89-99, 2018.

[9] M. R. Harahap, "Analisis Logam Arsenik (As) dan Kadmium (Cd) pada Sayur Bayam Hijau (Amaranthus tricolor) terhadap Bayam Merah (Blitum rubrum) dengan Metode Spektrofotometri Serapan Atom (SSA)," dalam Proceedings Ar-Raniry International Conference on Islamic Studies 1, 2016, pp. 500-505.

[10] S. Murniasih, K. Rozana, \& D. Swasti, "Asesmen Logam Berat Sampel Udara pada TSP di Sekitar PLTU Pacitan," Indonesian Journal of Chemical Analysis, vol. 03, no. 02, pp. 74-82, 2020.

[11] J. A. Grubb \& M. Nobles, "A Spatiotemporal Analysis of Arson," Journal of Research in Crime and Delinquency, vol. 53, no. 1, pp. 1-27, 2015.

[12] N. A. Afifah \& S. Notodarmojo, "Identifikasi Sebaran Logam Berat Arsen (As) dari Sistem Panas Bumi pada Air Tanah Dangkal dengan Metode Kriging," Jurnal Teknik Lingkungan, vol. 24, no. 1, pp. 27-40, 2018.

[13] Hazimah \& N. A. Triwuri, "Analisis Kandungan Arsenik (As) dan Cianida (CN) Depot Air Minum Isi Ulang di Kota Batam," Jurnal Rekayasa Sistem Industri, vol. 3, no. 2, pp. 129-133, 2018.

[14] Badan Standardisasi Nasional, Standar Nasional Indonesia (SNI) Batas Maksimum Cemaran Logam Berat dalam Pangan. Jakarta: Badan Standardisasi Nasional, 2009.

[15] H. E. Lasut, N. J. Kawung, \& M. T. Lasut, "Kandungan Arsen (As), Berbentuk Suspensi dan Terlarut, di Perairan Teluk Manado," Jurnal Pesisir dan Laut Tropis, vol. 1, no. 1, pp. 30-38, 2016.

[16] E. Fikri, O. Setiani, \& Nurjazuli, "Hubungan Paparan Pestisida dengan Kandungan Arsen (As) dalam Urin dan Kejadian Anemia ( Studi: Pada Petani Penyemprot Pestisida di Kabupaten Brebes)," Jurnal Kesehatan Lingkungan Indonesia, vol. 11, no. 1, pp. 29-37, 2012.

[17] Z. Šlejkovec, L. Gorše, A. Grobler, M. Jagodic, \& I. Falnoga, "Arsenic Speciation and Elemental Composition of Rice Samples from the Slovenian Market," Food Chemistry, vol. 342, 2021. 